\title{
A Regionalização Intramunicipal do Sistema Único de Saúde (SUS): um estudo de caso do município de São Paulo-SP, Brasil'
}

\author{
The Intramunicipal Regionalization of the Brazilian National \\ Health System (SUS): a case study in the city of São Paulo \\ (SP), Brazil
}

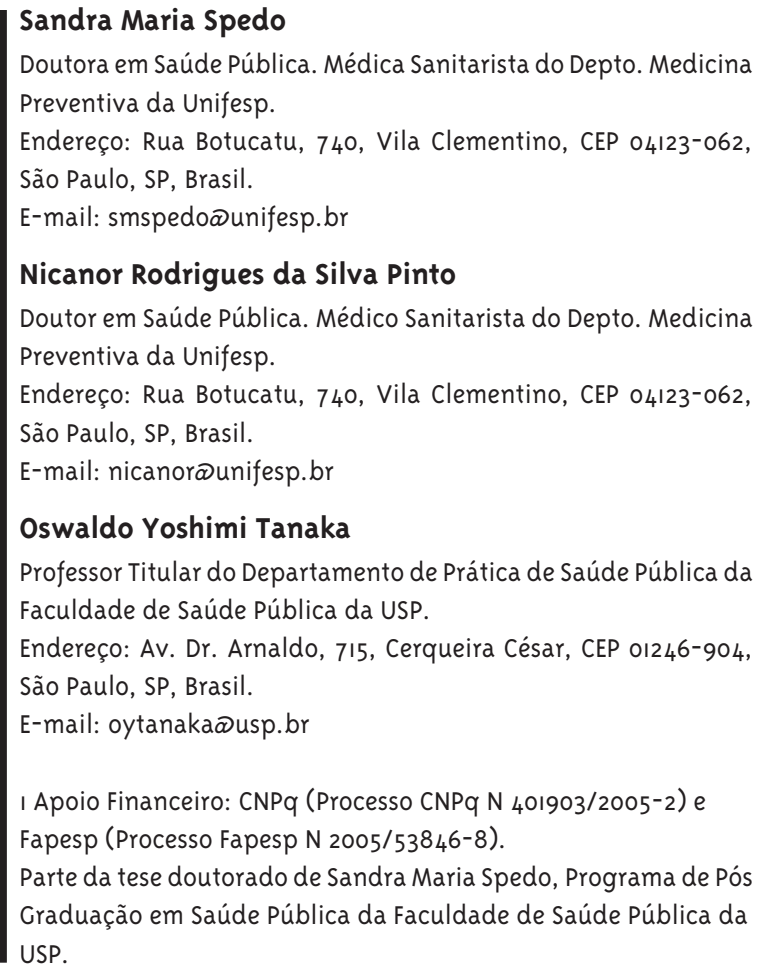

\section{Resumo}

A regionalização tem sido apontada como um dos principais desafios para viabilizar a equidade e a integralidade do SUS. Este artigo tem como objetivo avaliar o processo de implementação de um projeto de organização de regiões de saúde no município de São Paulo. Para tanto, foi realizado um estudo de caso em uma região selecionada desse município, a partir do referencial da análise de implantação, utilizando-se como fonte de dados documentos da gestão e entrevistas semiestruturadas com informantes-chave da gestão municipal 2005-2008. A análise temática evidenciou que o projeto de regionalização idealizado no início da gestão não foi efetivamente implementado. Dentre os fatores que interferiram nesse insucesso, destacam-se: a) a Secretaria Municipal de Saúde (SMS), além de seu caráter centralizador, manteve estruturas políticoadministrativas independentes para a gestão da atenção básica e da assistência hospitalar; b) a SMS não assumiu a gestão, de fato, de ambulatórios e hospitais estaduais; c) o poder institucional e a resistência dos hospitais em se integrar ao sistema de saúde. Discute-se, ainda, a necessidade de avançar na descentralização intramunicipal do SUS e buscar novas estratégias para a construção de pactos que consigam superar as resistências e articular instituições historicamente consolidadas, visando uma regionalização cooperativa e solidária.

Palavras-chave: Regionalização; Sistemas locais de saúde; Integralidade; Gestão em saúde; Política de saúde. 


\section{Abstract}

Regionalization has been pointed out as one of the most important challenges concerning the achievement of integrality and equity in the Brazilian National Health System (SUS). This study aims to evaluate the implementation process of a regional health project in the city of São Paulo. A case study was carried out in a selected region in the city based on the implementation assessment methodology. The data sources were management reports and interviews with key informants, and the period of analysis was 2005-2008. The thematic analysis showed that the regionalization project was not effectively implemented. The main factors involved in this failure were: a) the Municipal Health Department maintained a centralized decision-making process and a separate organizational framework for primary health care and for hospital care; b) specialized outpatient clinics and hospital facilities remained under the state level management and not under municipal responsibility; c) hospitals' strengthened institutional power generated resistance to integrate a comprehensive health system. The municipal decentralization process in the Brazilian National Health System (SUS) is still a challenge. It is important to identify new strategies to be able to improve the negotiation process among health managers, bringing together health organizations, in order to reach a cooperative and effective regionalization process within the National Health System in Brazil.

Keywords: Regional Health Planning; Local Health Systems; Integrality; Health Management; Health Policy.

\section{Introdução}

As duas primeiras décadas do Sistema Único de Saúde (SUS) foram marcadas por significativos avanços, em que pese uma conjuntura política e econômica desfavorável à implementação de uma reforma setorial. No entanto, ainda há importantes desafios para se caminhar no sentido de alcançar a “imagem objetivo" do SUS e, entre esses, destaca-se a regionalização (Campos, 2007).

No plano internacional, relata-se a existência de grande entusiasmo em relação à regionalização das políticas públicas, apesar da ausência de mudanças significativas decorrentes de experiências prévias. Esse movimento é associado, por um lado, às iniciativas de reestruturação das instituições visando sua democratização, maior participação social e aumento da eficiência. Por outro, mais recentemente, emerge também como solução potencial aos desafios da globalização e da necessidade de se reduzir o papel do planejamento central. A diversidade de significados de região em diferentes tempos, lugares e campos da política é identificada como um problema central para a análise desse processo (Tomblin, 2003).

A proposta de organizar sistemas de saúde regionalizados surgiu inicialmente na antiga União Soviética, pós-Revolução, tendo sido posteriormente adaptada para o ocidente por Dawson em 1920 (Silva e Mendes, 2004). Desde então, essa estratégia vem sendo adotada na estruturação de sistemas nacionais de saúde por diversos países. Nessas experiências, o paradigma dominante tem sido o da regionalização autárquica, na qual existe uma instância mesorregional, com relativa autonomia, responsável pela gestão do sistema local de saúde. Nesse contexto, o papel dos municípios é secundário, algumas vezes responsável apenas por ações de saúde pública, ou inexistente. Esse é o modelo adotado pelo Reino Unido, pela Itália e pelo Canadá, países cujos sistemas são referência para o SUS (Mendes, 2001, 2004).

No Brasil, em decorrência do padrão singular de descentralização implementado, desenvolveu-se um novo paradigma, o da municipalização autárquica, no qual o município é o principal responsável pela gestão do sistema de saúde local. Além de nosso país, 
esse modelo foi adotado apenas pela Finlândia que, inclusive, já o abandonou. Discute-se que essa forma de organização do sistema de saúde pode conduzir à fragmentação dos serviços, à perda da qualidade e à ineficiência na utilização de recursos (Silva e Mendes, 2004).

Com a promulgação da Constituição Federal de 1988, os municípios obtiveram autonomia inédita, transformando-se em entes federativos, com status jurídico semelhante ao dos estados e ao da União. Esse modelo de federalismo teria incentivado a prefeiturização, a concorrência entre os municípios, reforçando um "modelo predatório e não cooperativo de relações intergovernamentais" (Abrucio, 2005, p. 46). Considera-se, ainda, que esse processo pode produzir alguns efeitos perversos sobre as políticas públicas, tais como: "superposição de ações; desigualdades territoriais na provisão de serviços; e mínimos denominadores comuns nas políticas nacionais" (Arretche, 2004, p. 22).

Outro aspecto importante, nesse padrão de municipalização, está associado à indefinição do papel do ente estadual, o que teria propiciado uma posição de flexibilização dos governos estaduais que, muitas vezes, se eximiam ou repassavam suas atribuições para os municípios (Abrucio, 2005).

No setor saúde, a municipalização é associada com a constituição de sistemas municipais de saúde bastante heterogêneos e atomizados (Mendes, 2004; Gershman, 200o). Em várias regiões do país, esse processo ocorreu de "forma solitária, sem a devida cooperação técnica e financeira dos estados" (Solla, 2006, p. 341). No estado de São Paulo, foram identificadas situações em que mesmo municípios pequenos eram forçados a investir recursos próprios para organizar serviços de média e alta complexidade, sem qualquer racionalidade técnica ou econômica (Cecilio e col., 2007).

Nesse contexto, a regionalização dos serviços de saúde vem se impondo como uma estratégia para superar entraves advindos desse processo de municipalização. A implementação dessa diretriz, referenciada pelo princípio da equidade, possibilitaria constituir sistemas regionais com a participação solidária dos três entes federados (municípios, estado e união) visando garantir a integralidade da atenção.
Até o momento, pouco se avançou na implementação da regionalização no SUS. Os primeiros instrumentos normativos editados pelo Ministério da Saúde (MS) não priorizaram essa diretriz. Apenas em 2001, a Norma Operacional de Assistência à Saúde (NOAS 01/2001) mudou essa tendência, representando "uma iniciativa concreta e a primeira experiência regulamentadora da regionalização da saúde para o país como um todo" (Nascimento, 2007, p. 193).

Na NOAS/o1 (Brasil, 2002), a regionalização e a organização de sistemas funcionais foram destacadas como as principais estratégias para avançar o processo de descentralização do SUS em busca da equidade. No entanto, essa norma era centrada na organização da assistência no âmbito estadual, priorizando, para tanto, o processo de regionalização intermunicipal, não incorporando a dimensão intramunicipal, para os municípios de grande porte. A própria definição de municípios-polo não levou em consideração a vocação, os fluxos assistenciais preexistentes e a multiplicidade do papel a ser assumido por esses municípios. Caberia a eles garantir o acesso a serviços de saúde de distintos níveis de complexidade aos seus munícipes e à média e alta complexidade aos cidadãos encaminhados por outros municípios, dependentes dos recursos assistenciais disponíveis nesses polos.

Os gestores enfrentaram muitas dificuldades para aplicação dessa norma em decorrência da complexidade dos critérios técnicos estabelecidos, de difícil compreensão, implementação e acompanhamento, e, ainda, da ausência de mecanismos necessários para a negociação e pactuação de compromissos e responsabilidades entre os entes federados (Nascimento, 2007).

Em 2004, o MS desencadeou um processo de discussão junto à Comissão Intergestores Tripartite (CIT) com o objetivo de rever o processo normativo do SUS e buscar alternativas para os impasses e dificuldades enfrentados pelos gestores, assumindo a regionalização como uma das estratégias operacionais para implementar os princípios da integralidade e equidade. Esses atores institucionais, reconhecendo a crítica aos instrumentos normativos utilizados até então, propuseram a construção de um pacto entre os gestores das três esferas de governo. Esse pacto 
deveria induzir a uma inovação na gestão, qualificando-a para promover uma melhora do acesso aos serviços e da qualidade da atenção à saúde da população (Brasil, 2004; Silva e Dobashi, 2006).

O Pacto pela Saúde (Brasil, 2006) buscou superar os mecanismos de habilitação de estados e municípios contidos na NOB 01/96 e na NOAS SUS 2002. Propõe-se uma redefinição de responsabilidades coletivas, compartilhadas entre os gestores, centradas na necessidade de saúde da população, visando consolidar a descentralização do sistema na perspectiva da solidariedade, cooperação e autonomia dos entes federados (Silva e Dobashi, 2006).

A regionalização, eixo estruturante desse novo instrumento de gestão do SUS, deve orientar tanto o processo de descentralização das ações e serviços, quanto a própria pactuação entre gestores. A estratégia para operacionalizar e efetivar a regionalização está centrada na constituição de Regiões de Saúde, que podem assumir quatro formatos: intraestadual, intramunicipal, interestadual e fronteiriças.

O arranjo organizacional proposto para a estruturação dessas Regiões de Saúde foi a organização de redes de ações e serviços de saúde. No entanto, Andrade e Santos (2008, p. 30) advertem que o Pacto pela Saúde "não está composto por elementos que sejam capazes de transformar a regionalização hoje existente em uma verdadeira rede de serviços de saúde, que integre todos os entes federados de uma dada região". Para esses autores, tanto os estados quanto a União "ainda se sentem e agem como entes com maior poder decisório".

É importante considerar que a discussão e as propostas operacionais de regionalização do sistema de saúde sempre tiveram como foco principal a organização de sistemas regionais articulando municípios para promover a integração de serviços de distintas densidades tecnológicas. Ainda existe pouca discussão sistematizada sobre experiências de regionalização intramunicipal, particularmente em municípios-sede de regiões metropolitanas e capitais de estados, bem como sobre os desafios para o avanço desse processo.

Nesses municípios, a manutenção de arranjos institucionais preexistentes, marcados pela tradição e por múltiplos interesses consolidados e, por vezes, contraditórios, tem se constituído em entrave ao processo de organização de subsistemas regionalizados e integrados, no território intramunicipal, que permitam os necessários avanços do SUS nas áreas metropolitanas (Hall e Taylor, 2003; Gerschman e Santos, 2006).

Dessa forma, estudos sobre a regionalização intramunicipal em municípios de grande porte, em função de sua singularidade e complexidade-social, econômica e política -, podem contribuir para a compreensão e superação de problemas atuais do SUS.

Nesse contexto, o objetivo deste artigo é avaliar o processo de implantação de um projeto de organização de regiões de saúde no município de São Paulo, considerando seu potencial para promover a integralidade da assistência.

\section{Métodos}

O percurso metodológico deste estudo foi fundamentado na pesquisa avaliativa, em sua dimensão da análise de implantação, centrada em um projeto de intervenção, considerando-se o contexto organizacional. Alguns modelos de análise adaptados da teoria das organizações podem ser utilizados para esse fim. Entre esses, utilizou-se o modelo político, no qual a implantação de uma intervenção é entendida como um jogo de poder organizacional. Dessa forma, o sucesso ou fracasso da implantação de um projeto é associado mais aos interesses dos distintos atores, ao cenário político-institucional, do que ao seu planejamento (Denis e Champagne, 1997).

A partir desse referencial, optou-se pela estratégia de estudo de caso, que é caracterizado como uma investigação empírica de um fenômeno contemporâneo complexo inserido em algum contexto da vida real, especialmente quando os limites entre o fenômeno e o contexto não estão claramente definidos (Yin, 2005).

As fontes de evidência utilizadas foram: entrevistas com informantes-chave; documentos da gestão e atas ou memórias de reuniões. Para a realização das entrevistas, foram selecionados cinco gestores da Secretaria Municipal de Saúde de São Paulo (SMS-SP), sendo um assessor técnico do Gabinete da SMS, dois coordenadores regionais de saúde, um assistente técnico de uma das Coordenadorias Regionais de Saúde, e um supervisor técnico de saúde. 
As entrevistas foram não estruturadas, realizadas pelos próprios pesquisadores, gravadas e transcritas posteriormente. Os entrevistados foram esclarecidos sobre o tema central e, após uma explanação livre, os entrevistadores solicitavam o aprofundamento de alguns temas destacados na fala inicial.

A pesquisa abrangeu o período de uma gestão municipal da cidade de São Paulo (2005 a 2008), sendo que o trabalho de campo foi desenvolvido de 2006 a 2007. Considerando os objetivos do estudo, as dimensões territorial e populacional do município em questão, bem como sua complexidade, optou-se por delimitar este estudo a uma instância administrativa do nível regional da SMS-SP. Sua eleição foi baseada nos seguintes critérios: a existência de um número significativo de serviços públicos de saúde dos distintos níveis de complexidade; e a manutenção da unidade político-administrativa do território desde a retomada do SUS no município. A escolha da região foi, posteriormente, negociada com assessores da SMS-SP.

A região selecionada corresponde àquela sob a responsabilidade de uma Supervisão Técnica de Saúde (STS), abrangendo uma Subprefeitura com três Distritos Administrativos e com uma população residente estimada em cerca de 430 mil habitantes. Em termos populacionais, essa Subprefeitura é maior do que $96 \%$ dos municípios brasileiros (IBGE, 2001).

As STSs são instâncias subordinadas às Coordenadorias Regionais de Saúde (CRSs) e foram estruturadas segundo critérios populacionais, isto é, cada Supervisão deveria ser responsável por um território com cerca de 500 mil habitantes. A SMSSP é composta por cinco CRSs e 24 STSs. Neste artigo, com o objetivo de preservar o anonimato dos entrevistados, utiliza-se a denominação de CRS-1 para identificar a Coordenadoria correspondente à STS selecionada. A CRS-1 é responsável por cinco STSs, abrangendo o território de sete Subprefeituras e com população residente total estimada em cerca de 2,5 milhões de habitantes.

Mesmo com as mudanças ocorridas na estrutura político-administrativa da SMS-SP, o espaço territorial da STS selecionada corresponde àquele de estruturas regionais de gestões anteriores, desde o início do processo de implementação do SUS no município.
Essa foi considerada uma variável importante de contexto, na medida em que tal situação poderia representar fator facilitador para a organização de uma região de saúde.

O material coletado foi analisado utilizando-se a técnica da análise temática (Bardin, 2004). A partir do trabalho de campo, realizou-se a classificação e agregação dos dados e a identificação dos temas, que permitiram uma melhor aproximação da realidade estudada: o projeto de organização de regiões de saúde e o processo de implementação do projeto de regiões de saúde. 0 projeto foi caracterizado a partir dos documentos de gestão da SMS-SP e da CRS-1 e das entrevistas. A construção da narrativa sobre o processo de implantação baseou-se em fatos ou relatos identificados em entrevistas e atas ou memórias de reuniões dos Fóruns da CRS-1.

0 projeto de pesquisa, que gerou os dados utilizados neste artigo, foi aprovado pelos Comitês de Ética em Pesquisa da Faculdade de Saúde Pública da USP e da Secretaria Municipal de Saúde de São Paulo, com base na Resolução n ${ }^{\circ}$ 196/96 do Conselho Nacional de Saúde.

\section{Resultados}

\section{Um projeto de organização de regiões de saúde}

Em 2005, no início de uma nova gestão, a SMS-SP realizou uma reforma administrativa, pautada na reestruturação e na centralização do nível regional do SUS no município. Foram organizadas cinco novas CRSs a partir das Coordenadorias de Saúde preexistentes, que foram reagrupadas e transferidas das Subprefeituras para a SMS-SP. Para dar funcionalidade às novas CRSs, foram criadas 24 STSs (São Paulo, 2005a).

Constatou-se que o papel das CRSs ficou circunscrito à gestão dos serviços ambulatoriais próprios do município, não contemplando os demais serviços de saúde localizados em seu território. Manteve-se a separação político-administrativa entre atenção básica e a assistência hospitalar e de urgência e emergência. Essa permaneceu sob a gestão de cinco Autarquias Hospitalares que, posteriormente, foram transformadas em Coordenadorias Hospitalares Regionais (CHRs), subordinadas a uma Autarquia Hospitalar Municipal (São Paulo, 2008). 
Embora os limites territoriais das CRSs e das CRHs sejam coincidentes, esses se constituíram e se mantêm enquanto estruturas paralelas e independentes, observando-se a persistência da dificuldade de articulação entre as mesmas.

"Então, [teve] todo esse movimento de criar coordenadoria, tirar da subprefeitura, de juntar...; mas não se conseguiu mexer na lei. Com isso não se conseguiu mexer na lei da autarquia, a autarquia continua como uma cisão" (coordenador regional 2).

Outra questão importante do contexto políticoinstitucional da SMS-SP, observada durante o período da pesquisa, refere-se à significativa movimentação em seu quadro de direção. Na gestão 2005-2008, foram registradas três mudanças de secretários de saúde (quatro titulares) e, na região estudada, duas mudanças de coordenadores (três titulares) e quatro de supervisores (cinco titulares).

Paralelamente a essa reestruturação, foi proposta a divisão do município em 26 microrregiões. Para tanto, segundo relato do assessor técnico do gabinete da SMS-SP entrevistado, foi elaborado um diagnóstico de situação utilizando os parâmetros da Portaria $\mathrm{N}^{\circ} 1.101$ do Ministério da Saúde.

A necessidade de constituir um espaço regional para planejamento e organização do sistema de saúde nesse nível foi apresentada como uma das justificativas para o arranjo das microrregiões.

"Não tinha espaço onde os equipamentos, os responsáveis pelos serviços de saúde de determinada região sentassem juntos pra conversar. Inclusive, uma das propostas de organização foi se pensar em termos de acesso, não de divisão administrativa" (assessor técnico do gabinete da SMS-SP).

As microrregiões não seriam constituídas enquanto estruturas político-administrativas. A proposta previa a manutenção das CRSs e STSs e a definição de novos arranjos espaciais para as microrregiões, que não seguiam, necessariamente, a mesma divisão das STSs. Segundo o mesmo entrevistado, a microrregião não era para "ser uma estrutura formal. [...] Ela éfuncional. É uma forma de você pensarna organização do sistema" (assessor técnico do gabinete da SMS-SP).

"A lógica é que tenha acesso à população. [...] De forma que toda microrregião tenha um hospital geral. [...] Eram microrregiões onde [...], até o nível secundário da atenção, [...] se pudesse resolver o próprio planejamento dessa programação, dos serviços ali daquela região" (assessor técnico do gabinete da SMS-SP).

Os relatos dos distintos gestores entrevistados evidenciaram que o hospital foi considerado o núcleo central, a partir do qual a microrregião seria organizada. "A lógica seria a área de influência de um hospital" (coordenador regional 2).

"Inicialmente [...] foi realizada a divisão de áreas na região 1 e na secretaria como um todo, em microrregiões, onde a gente relacionava o hospital da região com os ambulatórios e as unidades básicas do entorno" (assistente técnico da CRS-1).

A organização de Fóruns foi a estratégia operacional assumida para a implementação das microrregiões, figurando entre as prioridades da CRS-1, definidas no início do governo. Identificou-se que esse tema foi abordado em dois documentos internos da gestão, elaborados pela equipe técnica dessa CRS: a) Diagnóstico Situacional da Coordenadoria Regional de Saúde 1 (CRS-1), que contém um diagnóstico regional propriamente dito e o Planejamento Plurianual (PPA 2006-2009) da região; b) Organização dos Fóruns de Planejamento e Regulação da Região 1.

De acordo com o documento intitulado Diagnóstico Situacional da CRS-1, em março de 2005, constituíram-se grupos específicos denominados Fóruns, que teriam a atribuição de identificar os nós críticos, elaborar e implementar projetos, objetivando o planejamento e a organização do sistema de saúde regional. Estavam previstos um Fórum Regional, três Fóruns de Macrorregião (Ma) e um número não definido de Fóruns de Microrregião (Mi), representados graficamente na Figura 1. Estes seriam constituídos por distintos atores sociais, representantes das instituições e dos serviços que atuavam na região, desde gestores do nível central da SMS-SP e da SES-SP, gerentes dos serviços públicos, e as instituições privadas "parceiras" da SMS-SP na região.

"Qual que era a proposta da microrregião? Que a gente fizesse fóruns por microrregião e esses fóruns deviam incluir todos os prestadores da microrregião, sejam municipais, sejam estaduais, sejam não públicos" (coordenador regional 2). 

Figura I - Esquema da organização das Regiões e Fóruns
na CRS-I, SMS-SP

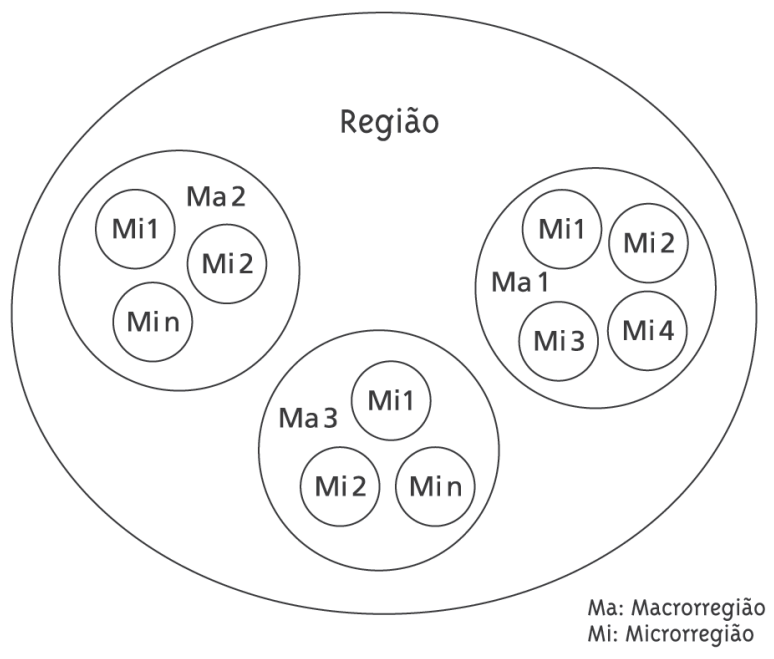

No PPA 2006-2009 regional, organizado a partir de programas e em consonância com o PPA 20062009 municipal, a organização e a continuidade dos distintos Fóruns foram destacadas entre as ações propostas para o programa "SUS com Qualidade". Cabe ressaltar que o PPA contemplou, ainda, uma meta relacionada ao número de fóruns realizados, dentre os indicadores propostos para o monitoramento da gestão.

No documento Organização dos Fóruns de Planejamento e Regulação da Região 1 consta que os Fóruns deveriam acompanhar "desde o planejamento e a organização global do sistema de saúde regional até o acompanhamento e avaliação das ações no território de abrangência de cada unidade de saúde, permeando atenção básica, ambulatorial e hospitalar". No entanto, a composição dos Fóruns apresentada nesse mesmo documento não previa a participação de todos os serviços de saúde localizados e/ou integrantes do sistema locorregional do SUS na região estudada. Tanto as unidades que concentram ações de atenção básica quanto os ambulatórios de especialidades participariam apenas dos Fóruns de Microrregião, e os serviços privados conveniados não foram incorporados. Evidenciouse, assim, uma contradição nos dois documentos internos da CRS-1, entre os objetivos e a composição dos Fóruns, que excluía atores fundamentais para viabilizar o projeto.

\section{Os (des)caminhos do projeto de regiões de saúde}

Pode-se constatar que o projeto de implementação de regiões de saúde, apresentado acima, foi elaborado no nível central da SMS-SP e, posteriormente, apresentado aos níveis regionais para discussão. No decorrer do processo, a assessoria da SMS-SP buscou estabelecer um diálogo com dirigentes da Secretaria de Estado da Saúde (SES-SP) visando ampliar a governabilidade e viabilizar a operacionalização do projeto, na medida em que vários serviços especializados ainda se encontravam sob a gestão estadual.

"Estado e município não conseguem ter uma visão do sistema como um todo e ver que o município é o gestor. Hoje, o município é gestão plena! [...] $O$ estado até estava participando junto, eu já tinha conversado já com o [assessor técnico de coordenação da SES-SP-ATC].O [coordenador da SES-SP] já tinha concordado, o [ATC] ia junto em algumas reuniões. [...] Era o recado do governo do estado para os serviços do estado que era para eles estarem sentando juntos" (assessor técnico do gabinete da SMS-SP).

A organização das microrregiões não ocorreu de modo uniforme em todo o município, "algumas coordenações desencadearam, outras não. [...] Na construção do processo, das propostas, algumas delas já foram levando em conta o resultado das reuniões, do processo" (assessor técnico do gabinete da SMS-SP).

É oportuno ressaltar que a CRS-1 foi coordenada, no início da administração municipal, pelo mesmo gestor que, posteriormente, assumiu o cargo de assessor técnico do gabinete da SMS-SP. Esse fato pode estar associado à implementação precoce do projeto nessa região, em um momento anterior à própria apresentação da proposta às demais regiões do município.

"A CRS-1 foi a primeira que saiu à frente nessa questão de fórum de micro porque a ... (assessor técnico do gabinete da SMS-SP) [...] tinha essa experiência do Estado, que [...] ela trouxe pra gente" (coordenador 1).

A primeira reunião do Fórum Regional da CRS-1 foi realizada em março de 2005, logo no início da gestão municipal, período em que o ator em questão ocupava o cargo de coordenador regional. Essa reunião foi representativa, contando com a presença de 47 pessoas, 
representando distintas instâncias gestoras do SUS no município e serviços de saúde (Tabela 1). 0 coordenador da CRS-1 apresentou a proposta de organização dos Fóruns, contemplando o objetivo e a composição dos Fóruns Regional e das Macrorregiões. Em relação aos Fóruns de Microrregiões, foi proposto que cada hospital geral estabelecesse sua área de abrangência e se reunisse com as Unidades Básicas de Saúde (UBS) s, os ambulatórios de especialidade, os serviços conveniados e os prestadores de serviço para realizarem ações integradas. $\mathrm{O}$ assessor de gabinete de SMS-SP presente sugeriu, ainda, a constituição de um "comitê deliberativo" com a atribuição de definir o que cada hospital deveria fazer, e ressaltou a importância do encontro e da conjuntura política, em que o mesmo partido político ocupava os governos do estado e do município de São Paulo.

Contudo, apesar dessa avaliação política favorável e da representatividade da reunião, a leitura da ata evidenciou que a discussão ficou limitada apenas ao relato das dificuldades enfrentadas no cotidiano dos serviços presentes, e não foi possível identificar qualquer encaminhamento para as questões levantadas. Foram agendadas uma nova reunião desse Fórum e as primeiras dos Fóruns de Macrorregião.

A segunda reunião do Fórum Regional aconteceu três meses após a primeira, na data previamente agendada. No entanto, o número de participantes e a representatividade da reunião foram signifi-

Tabela I - Número de participantes e de Instituições e serviços participantes das reuniões do Fórum Regional e do Fórum da Macrorregião-I da CRS-I. São Paulo (SP), 2005.

\begin{tabular}{|c|c|c|c|c|c|c|c|c|}
\hline \multirow[b]{3}{*}{ Instituição } & \multicolumn{4}{|c|}{ Regional } & \multicolumn{4}{|c|}{ Macrorregião-ı } \\
\hline & \multicolumn{2}{|c|}{$\mathrm{I}^{\mathrm{a}}$ reunião } & \multicolumn{2}{|c|}{$2^{\mathrm{a}}$ reunião } & \multicolumn{2}{|c|}{$1^{\mathrm{a}}$ reunião } & \multicolumn{2}{|c|}{$2^{\mathrm{a}}$ reunião } \\
\hline & Participantes & Instituições & Participantes & Instituições & Participantes & Instituições & Participantes & Instituições \\
\hline SMS-SP & 23 & 17 & 21 & 13 & 14 & 7 & 7 & 5 \\
\hline Assessoria de Gabinete & 6 & 4 & 4 & 1 & 2 & 1 & - & - \\
\hline $\begin{array}{l}\text { Coordenadoria e } \\
\text { Supervisões }\end{array}$ & 10 & 6 & 9 & 6 & 7 & 3 & 5 & 3 \\
\hline Autarquia Hospitalar & 2 & 2 & 3 & 1 & 2 & 1 & 1 & 1 \\
\hline Hospital e Pronto-socorro & 5 & 5 & 5 & 5 & 3 & 2 & 1 & 1 \\
\hline $\begin{array}{l}\text { Ambulatório de } \\
\text { Especialidades }\end{array}$ & - & - & - & - & - & - & - & - \\
\hline UBS e PSF & - & - & - & - & - & - & - & - \\
\hline SES-SP & 15 & 9 & 3 & 3 & 3 & 2 & 2 & 2 \\
\hline Assessoria de Gabinete & 2 & I & 1 & 1 & 1 & 1 & 1 & 1 \\
\hline Hospital & 13 & 8 & 2 & 2 & 2 & 1 & 1 & 1 \\
\hline $\begin{array}{l}\text { Ambulatório de } \\
\text { Especialidades }\end{array}$ & - & - & - & - & - & - & - & - \\
\hline Outras & 9 & 3 & 2 & 2 & 2 & 2 & - & - \\
\hline Hospital universitário & 1 & 1 & 1 & 1 & 1 & 1 & - & - \\
\hline $\begin{array}{l}\text { "Parceiro" privado de } \\
\text { SMS-SP }\end{array}$ & 6 & 1 & I & 1 & - & - & - & - \\
\hline $\begin{array}{l}\text { Hospital privado } \\
\text { prestador SUS }\end{array}$ & - & - & - & - & - & - & - & - \\
\hline Outros & 2 & 1 & - & - & 1 & 1 & - & - \\
\hline TOTAL & 47 & 29 & 26 & 18 & 19 & 11 & 9 & 7 \\
\hline
\end{tabular}

Fonte: atas e memórias das reuniões da CRS-I (2005). 
cativamente menores, marcada pela ausência de hospitais vinculados à SES-SP. De um total de oito hospitais previstos em sua composição, apenas dois compareceram (Tabela 1).

O Fórum da Macrorregião-1 realizou sua primeira reunião em maio de 2005, com a presença de 19 pessoas que representavam instituições ou serviços que atuavam nessa região (Tabela 1). Os presentes relataram dificuldades enfrentadas no cotidiano da gestão e algumas alternativas utilizadas para superá-las. Na ata dessa reunião, não foram registradas a discussão e nem a proposta de encaminhamento para essas questões. O próprio Fórum registrou e destacou a ausência de três, dos quatro hospitais estaduais componentes do mesmo e cujos serviços são essenciais para a organização de um sistema de referência regional.

A segunda reunião desse Fórum foi realizada no mês seguinte, com um número menor de participantes, destacando-se a ausência não justificada de todos os hospitais vinculados à SES-SP, componentes do mesmo. 0 único hospital representado pertencia a outra macrorregião. Os participantes expuseram alguns problemas relativos à referência para os serviços de especialidade. Propôs-se a constituição de quatro microrregiões, a partir dos hospitais de referência.

A partir de junho de 2005, mês em que essa reunião foi realizada, não foram identificadas quaisquer outras reuniões, tanto do Fórum Regional, quanto da Macrorregião-1. As entrevistas com o coordenador e um assistente técnico da CRS-1 corroboraram esse fato:

"(Os Fóruns) estão parados a partir desse mês de julho porque algumas coisas a gente não tinha governabilidade, a gente não, o grupo que tava participando" (coordenador 1).

"Por um ano a gente conseguiu manter minimamente essas reuniões de micro e de macro. Esse fórum maior, de macrorregião, a gente só teve em duas ocasiões. [...] Em julho de 2006 foi solicitado que a gente tentasse ter reuniões mais produtivas. $\varepsilon$, chegou uma hora em que foi determinado: 'vamos dar um tempo', porque não estava caminhando em ganhos" (assistente técnico da CRS-1).

Nas atas disponibilizadas, não houve registro de qualquer reunião do Fórum da Microrregião-1, fato esse confirmado na entrevista com o supervisor da região. Cabe destacar que o hospital, a partir do qual seria organizada essa microrregião, esteve representado apenas na primeira reunião, tanto do fórum regional quanto do macrorregional do qual era componente.

"O hospital X, ele faz parte também da nossa microrregião, e existem aqui as reuniões de microrregião. $\varepsilon$, eu estou aqui já desde dezembro, como eu falei, e até agora não foi agendada nenhuma reunião de micro" (supervisor).

No entanto, constatou-se a ocorrência de três reuniões do Fórum da Microrregião-2, em meses consecutivos. Ressalte-se que o hospital localizado na Microrregião-1 é vinculado à SES-SP, enquanto o da Microrregião-2 é municipal. É importante destacar, ainda, que duas das quatro microrregiões propostas para a Macrorregião-1 seriam organizadas a partir de hospitais vinculados à SES-SP, uma a partir de hospital universitário, e a outra, de hospital próprio do município. De acordo com as atas, o único Fórum que se constituiu, de fato, foi aquele vinculado ao hospital municipal. Ao que parece, o envolvimento dos serviços nos Fóruns pode estar relacionado, entre outros fatores, com sua vinculação institucional.

A análise das atas permitiu identificar que ocorreu um significativo esvaziamento dos Fóruns como conseqüência, em grande medida, da não participação dos hospitais vinculados à SES-SP. Dentre os 13 hospitais sob gestão estadual constituintes do Fórum Regional, e presentes em sua primeira reunião, apenas dois compareceram à segunda.

Evidenciou-se, ainda, que, apesar do objetivo manifesto ter sido a constituição de microrregiões, a estratégia adotada para implementação do projeto privilegiou os níveis regional e macrorregional. As microrregiões, que seriam organizadas a partir desses espaços, não foram efetivamente implementadas.

Alguns atores entrevistados associaram a interrupção dos Fóruns à baixa governabilidade dos gestores regionais do SUS no município. Nesse sentido, é interessante observar a semelhança entre os relatos de dois gestores entrevistados em separado e em momentos distintos:

"Chegou um momento que a gente começou a perceber [...] que havia muitos fóruns de micro e as 
pessoas que desciam pra discutirno fórum não eram as pessoas que tinham governabilidade pra resolver nada. Então, você ia, ia, ia, falava, falava e não resolvia. Daí eu disse 'suspende qualquer reunião de micro agora, vamos tentar resolver esses nós que foram todos elencados, vamos discutir porque dependia da secretaria, dependia de situações de estado'. [...] Então essa governabilidade, a gente tem que levar pra secretaria essa discussão" (coordenador 1 ).

"Chegou uma hora que realmente travou o processo. Foi determinado que essas reuniões iam diminuir porque precisava ter minimamente uma autonomia maior. Mas, chegou uma hora em que não tinha essa autonomia mesmo, no sentido de aumentar os recursos, porque dependia da política geral, seja do município, seja do estado" (assistente técnico da CRS1).

As reflexões do assessor técnico do gabinete da SMS-SP, acerca das dificuldades enfrentadas para implementar esse projeto, incorporaram outros aspectos da política institucional para justificar a interrupção dos Fóruns.

"Eu acho que isso é assim uma coisa mais instituída. Faz parte da cultura. [...] O objetivo dos encontros era muito mais no sentido de pactuar os serviços. [...] Mudou o governo, mas as pessoas são as mesmas [...] você tem que mudar um pouco essa cultura e fazer, também, com que se enxergue que, na verdade, tem que ter um olhar da gestão, de fato, do sistema. [...] Cada um tem uma visão do que está acontecendo no sistema. Só que de uma forma fragmentada" (assessor técnico do gabinete da SMS-SP).

O insucesso do projeto foi relacionado, também, ao fato de que a SMS-SP não o assumiu enquanto uma de suas prioridades políticas. Segundo um dos coordenadores entrevistados, o projeto, apesar de muito bom tecnicamente, ficou vinculado ao técnico que o idealizou, apesar de o mesmo ter ocupado cargo de confiança junto ao gabinete do secretário.

"Era um projeto do lassessor técnico do gabinete da SMS-SP]. Quando ele sai ninguém encabeça esse projeto de verdade, mas ele tinha muita consistência, do nosso ponto de vista dos coordenadores. [...] Não vou dizer que ele sumiu; ninguém disse pra mim 'olha esqueça o [projeto]' mas ninguém incentivou que aquilo andasse" (coordenador 2).
Considerando-se as questões e dificuldades registradas na implementação das microrregiões, foram levantadas hipóteses sobre fatores que podem ter condicionado a curta duração desse espaço potencial de gestão regional. Entre elas são destacadas as seguintes: a) a SMS-SP tinha baixa governabilidade para conduzir esse processo, na medida em que vários hospitais e ambulatórios de especialidades permaneciam sob a gestão da SES-SP; b) o nível regional (CRS) da SMS-SP, responsável pela coordenação do processo, tinha pouca autonomia e baixa governabilidade, dado o caráter centralizador da gestão municipal; c) a construção do projeto não comprometeu todos os atores estratégicos para sua operacionalização; e) poder institucional dos hospitais e sua resistência em se integrar a um sistema de saúde.

\section{Discussão}

A concepção de região de saúde e as estratégias utilizadas para sua implementação, no município de São Paulo, refletem as orientações da política de saúde do período estudado, particularmente em relação ao modelo de atenção e ao caráter centralizador da gestão.

A prioridade conferida pela SMS-SP a esse projeto é outra variável que foi incorporada nessa análise. As constantes trocas de secretários municipais de saúde, observadas durante o período em estudo, podem indicar mudanças na orientação das políticas de saúde da SMS-SP, com repercussões nas suas prioridades. Assim, a viabilidade de um projeto apresentado no início da gestão, independentemente de sua qualidade técnica, tende a ser comprometida.

O hospital foi apresentado como o núcleo central da região de saúde, isto é, as microrregiões seriam organizadas a partir dele. A centralidade do hospital no modelo proposto ficou mais evidente a partir da análise da composição dos fóruns. Os serviços da atenção básica, os ambulatórios de especialidades e os prestadores privados da região estudada não foram integrados em qualquer etapa do projeto. Não se observou, tampouco, a preocupação de envolver representações de usuários e de trabalhadores da saúde nesse processo.

Não foi evidenciado processo de discussão e 
negociação prévia com os hospitais para que assumissem o papel proposto. A implantação dos fóruns foi conduzida pela Coordenadoria Regional de Saúde que era responsável apenas pela assistência ambulatorial, não tendo relação institucional direta com os hospitais, os quais estavam subordinados a outra estrutura da SMS-SP.

Essa situação era agravada pelo fato de que a SMS-SP, no processo de habilitação em gestão plena do sistema, não assumiu os ambulatórios de especialidade e hospitais estaduais, que continuaram sob a gestão de fato da SES-SP. Esse arranjo político organizacional, no município de São Paulo, por um lado, retrata a condição de baixa governabilidade do próprio gestor municipal em relação a esses serviços públicos de saúde (Pinto e col., 2009). Por outro, reforça a necessidade de processos de negociação, visando à construção de consensos entre distintos atores, tal qual proposto no Pacto pela Saúde (Brasil, 2006). No entanto, não se observaram evidências que demonstrassem o interesse da SES-SP em pactuar a gestão de seus serviços com a SMS-SP. Cabe destacar que, no período estudado, o governo do estado implementou uma reestruturação daquela secretaria, reafirmando seu papel na gestão dos serviços ambulatoriais e hospitalares sediados na capital paulista. Nessa mesma direção, outros estudos (Oliveira, 2003; Solla, 2006) relataram a resistência do gestor estadual em implementar a gestão compartilhada ou a transferência de serviços para a esfera municipal, em particular em regiões onde o estado tinha maior tradição e estrutura de serviços de saúde, como é o caso do município de São Paulo.

Nesse cenário, o gestor regional do SUS municipal não teve, e dificilmente terá, governabilidade para coordenar a regionalização dos serviços de saúde, um processo complexo que demanda articulação e pactuação políticas entre distintos atores institucionais e sociais com interesses, por vezes, conflitantes. Na medida em que os atores presentes nessa arena política identificam a fragilidade desse gestor, mantém-se a resistência às propostas de integração interinstitucional. É importante considerar que os distintos atores sociais, geralmente, ponderam e calculam sobre as vantagens, para sua posição, antes de aderir a qualquer projeto dessa magnitude (Matus, 1993; Coelho, 1998).
Outra questão importante a ser considerada na análise desse contexto está relacionada com a influência que políticas de saúde prévias e o desenho institucional exercem na conformação de uma determinada política de saúde (Hall e Taylor, 2003). Nesse sentido, destacam-se a trajetória e o lugar ocupado pelos hospitais no sistema de saúde brasileiro, na medida em que seu desenvolvimento foi marcado por um modelo que privilegiou a assistência médica hospitalar, com forte apoio do Estado. Ao mesmo tempo em que a instituição Hospital assumia grande centralidade no sistema de saúde, paradoxalmente, aumentava sua independência em relação ao mesmo. Cabe destacar, ainda, que os hospitais, inclusive os públicos, constituíram-se a partir de uma lógica organizacional específica, com um sistema próprio de normas e valores, e desfrutam, até hoje, de uma considerável autonomia para estabelecer sua clientela e definir a modalidade assistencial ofertada (Campos, 1992; Carapinheiro, 1993).

o SUS, apesar de contemplar em seu projeto inicial críticas a esse modelo, foi implementado sobre a estrutura e lógica do extinto INAMPS (Instituto Nacional de Assistência Médica da Previdência Social), no qual o hospital era o núcleo central da assistência (Trevisan, 2007). No caso do município de São Paulo, é importante lembrar que grandes hospitais públicos, de hoje, foram construídos e instituídos pelos antigos IAPs (Institutos de Aposentadorias e Pensões), tendo sido incorporados pelo INAMPS e, posteriormente, pela SES-SP. Desde sempre funcionaram de forma autônoma e com muita resistência em se articularem com os demais serviços de saúde vinculados à SES-SP e, particularmente, à SMS-SP. Essa situação pouco se alterou, pois até 2008 os mesmos continuavam sob a gestão da SES-SP.

Considerando que a regionalização do sistema de saúde caminha pari passu à descentralização, é condição para sua operacionalização o fortalecimento da capacidade de governo e da governabilidade dos governos locais, particularmente em relação a setores que tradicionalmente não se submetiam ao controle da esfera municipal (Silva e Mendes, 2004; Lima, 2005). Quando esse processo ocorre internamente a um município, há que se considerar o papel estratégico que o gestor regional do SUS, no âmbito municipal, deve desempenhar em sua condução. 


\section{Considerações Finais}

O projeto de regionalização proposto para o município de São Paulo apresentava uma racionalidade técnica coerente com os atuais desafios do SUS, na medida em que visava organizar sistemas de saúde funcionais, a partir de processos de pactuação e integração entre diferentes serviços de saúde. No entanto, apesar de ter sido idealizado por assessores do Gabinete da SMS-SP, esse projeto não teve sustentação política, não tendo sido incorporado na agenda de prioridades da gestão municipal. Alguns elementos dessa política municipal de saúde eram, inclusive, muito desfavoráveis para sua viabilidade. Dentre eles, destacam-se a centralização da gestão, com o esvaziamento técnico e político do nível regional, e a separação político-administrativa entre atenção básica e assistência hospitalar, agravada pela resistência da SES-SP em integrar os serviços sob sua gestão ao SUS municipal.

A despeito dos constrangimentos da política municipal de saúde, foi apresentado um projeto que teria potencial para desencadear um processo de regionalização mais funcional e racional, a partir do nível local. Contudo, a proposta foi operacionalizada seguindo a lógica formal centralizadora da gestão, privilegiando o espaço macrorregional, mais estrutural, em detrimento do microrregional, mais funcional.

A trajetória dessa iniciativa de regionalização intramunicipal em São Paulo evidenciou, por um lado, a falta de apoio político da própria gestão da SMS-SP para implementá-la e, por outro, o não envolvimento de todos os atores estratégicos para a constituição de uma região de saúde. Foram privilegiados os hospitais, que por sua história institucional e pelo próprio contexto atual da saúde no município não reconheciam a autoridade do gestor municipal para coordenar o processo. A estratégia utilizada para organizar espaços para pactuação e construção da regionalização não teve potência para envolver e sensibilizar os distintos atores. Devem-se considerar, ainda, possibilidades e limites para se implementar um processo de regionalização sem a garantia de estruturas organizacionais que lhe dêem sustentação.
A implementação de uma regionalização da saúde, de caráter cooperativo e solidário, implica na construção de um processo contínuo e sustentável de negociação. Nesse sentido, considera--se estratégica a busca de consensos em torno de grandes objetivos compartilhados entre todos os atores sociais implicados no processo, respeitando ainda seus interesses particulares (Fleury, 2002). Esses elementos sugerem a magnitude do desafio a ser enfrentado no processo de implementação do Pacto pela Saúde, na medida em que a negociação dos termos de compromisso deve contar, necessariamente, com a participação de todos os atores estratégicos para a construção das novas regiões de saúde.

Por fim, considerando o contexto do federalismo brasileiro, é fundamental constituir e avaliar novos arranjos de coordenação intergovernamental no âmbito do SUS, visando superar a atual situação de compartimentalização, concorrência e conflito entre entes federativos. No entanto, deve-se avaliar a potência de um projeto de pactuação dessa natureza, restrito apenas ao setor saúde.

\section{Referências}

ABRUCIO, F. L. A coordenação federativa no

Brasil: a experiência do período FHC e os desafios do governo Lula. Revista de Sociologia e Política, Curitiba, n. 24, p. 41-67, 2005.

ANDRADE, L. O. M.; SANTOS, L. Redes

interfederativas de saúde e o SUS. Divulgação em Saúde para Debate, Rio de Janeiro, n. 42, p. 27-34, 2008.

ARRETCHE, M. Federalismo e políticas sociais no Brasil: problemas de coordenação e autonomia. São Paulo em Perspectiva, São Paulo, v. 18, n. 2, p. 17-26, 2004.

BARDIN, L. Análise de conteúdo. 3. ed. Lisboa: Ed. 70, 2004.

BRASIL. Ministério da Saúde. Portaria nº 373, de 27 de fevereiro de 2002. Norma Operacional da Assistência à Saúde - NOAS-SUS 01/02: estabelece o processo de regionalização como estratégia de hierarquização dos serviços de saúde. Diário Oficial da União. Brasília, DF, 28 fev. 2002. Seção I, p. 52. 
BRASIL. Ministério da Saúde. Portaria n. 399, de 22 de fevereiro de 2006. Divulga o Pacto pela Saúde 2006 - Consolidação do SUS e aprova as diretrizes operacionais do referido pacto. Diário Oficial da União. Brasília, DF, 23 fev. 20o6. Seção I, p. 43.

BRASIL. Conselho Nacional de Secretários de Saúde (CONASS). Pacto de gestão. Brasília, DF, 2004. (Nota Técnica, 26/o4). Disponível em: <http://www.conass.org.br/?page=publicacao_ notas\&ano=2004>. Acesso em: 15 ago. 2008.

CAMPOS, G. W. S. Reforma da reforma: repensando a saúde. São Paulo: Hucitec, 1992.

CAMPOS, G. W. S. Reforma política e sanitária: a sustentabilidade do SUS em questão. Ciência e Saúde Coletiva, Rio de Janeiro, v. 12, n. 2, p. 307$317,2007$.

CARAPINHEIRO, G. Saberes e poderes no hospital: uma sociologia dos serviços hospitalares. 2. ed. Porto: Ed. Afrontamento, 1993. p. 17-43.

CECÍLIO, L. C. O. et al. O gestor municipal na atual etapa de implantação do SUS: característica e desafios. Revista Eletrônica de Comunicação Informação e Inovação em Saúde, Rio de Janeiro, v. 1, n. 2, p. 200-207, 2007. Disponível em: http:// www.reciis.cict.fiocruz.br/index.php/reciis/ article/view/84/79. Acesso em: 10 set. 2008.

COELHO, V. S. Interesses e instituições na política de saúde. Revista Brasileira de Ciências Sociais, São Paulo, v. 13, n. 37, p. 115-128, 1998.

DENIS, J.; CHAMPAGNE, F. Análise da implantação. In: HARTZ, Z. M. A. (Org.). Avaliação em saúde: dos modelos conceituais à prática na análise da implantação de programas. Rio de Janeiro: Fiocruz, 1997. p. 49-88.

FLEURY, S. El desafío de la gestión de las redes de políticas. Revista Instituciones y Desarrollo, Barcelona, n. 12/13, p. 221-247, 2002.

GERSCHMAN, S. A descentralização da política de saúde no final dos anos 199o. Revista de Administração Pública, Rio de Janeiro, v. 34, n. 4, p. 147-170, 2000.
GERSCHMAN, S; SANTOS, M. A. B. O Sistema Único de Saúde como desdobramento das políticas de saúde do século XX. Revista Brasileira de Ciências Sociais, São Paulo, v. 21, n. 61, p. 177-227, 2006.

HALL, P. A.; TAYLOR, R. C. R. As três versões do neo-institucionalismo. Lua Nova, São Paulo, n. 58, p. 193-223, 2003.

IBGE - INSTITUTO BRASILEIRO DE GEOGRAFIA E ESTATÍSTICA. Perfil dos municípios brasileiros: gestão pública 2001. Rio de Janeiro: IBGE, 2003. Disponível em: <http://www.ibge.gov.br/home/ estatistica/economia/perfilmunic/2001/default. shtm>. Acesso em: 15 maio 2008.

LIMA, L. L. Gestão da política de saúde no município: a questão da autonomia. 2005. Dissertação (Mestrado em Sociologia) Universidade Federal do Rio Grande do Sul, Porto Alegre, 2005.

MATUS, C. Política, planejamento e Governo. Brasília, DF: IPEA, 1993. tomo I, p.29-62.

MENDES, E. V. Os grandes dilemas do SUS. Salvador: Casa da Qualidade, 2001.

MENDES, E. V. O SUS que temos e o SUS que queremos. In: BRASIL. Conselho Nacional de Secretários de Saúde (CONASS). Convergências e divergências sobre a gestão regionalizada do SUS. Brasília, DF, 2004. p. 28-61.

NASCIMENTO, V. B. SUS: pacto federativo e gestão pública. São Paulo: Hucitec; Santo André: Cesco, 2007.

OLIVEIRA, M. H. C. B. Pactos de gestão: divisão de responsabilidades entre estados e municípios na descentralização. In: PIERANTONI, C. R.; VIANNA, C. M. M. (Org.). Gestão de sistemas de saúde. Rio de Janeiro: UERJ, IMS, 2003. p. 59-92.

PINTO, N. R. S.; TANAKA, O. Y.; SPEDO, S. M. Política de saúde e gestão no processo de (re) construção do SUS em município de grande porte: um estudo de caso de São Paulo, Brasil. Cadernos de Saúde Pública, Rio de Janeiro, v. 25, n. 4, p. 927938, 2009. 
SÃO PAULO. Decreto n. 46.209. Dispõe sobre a transferência das Coordenadorias de Saúde das Subprefeituras que especifica para a Secretaria Municipal de Saúde. Diário Oficial do Município de São Paulo, 16 ago. 2005. Folha 1. Disponível em: <http://www3.prefeitura.sp.gov.br/cadlem/ secretarias/negocios_juridicos/cadlem/integra. asp?alt=16082005D\%204620900oo >. Acesso em: 10 jun. 2008.

SÃO PAULO. Decreto n. 49.331, de 19 de fevereiro de 2008. Regulamenta a lei $n^{0} 14.669$ no que se refere à organização e estruturação da Autarquia Hospitalar Municipal. Diário Oficial do Município de São Paulo, 20 fev. 2008. Folha 1.

SILVA, M. V. C. P.; MENDES, E. V. Pacto de gestão: da municipalização autárquica à regionalização cooperativa. Belo Horizonte: Secretaria de Estado de Saúde de Minas Gerais, 2004.
SILVA, S. F.; DOBASHI, B. F. Um novo pacto no SUS. Divulgação em Saúde para Debate, Rio de Janeiro, n. 34, p. 9-17, 2006.

SOLLA, J. J. S. P. Avanços e limites da descentralização no SUS e o "Pacto de Gestão". Revista Baiana de Saúde Pública, Salvador, v. 30, n. 2, p. 332-348, 2006.

TOMBLIN, S. Ability to manage change through regionalization: theory versus practice. [paper presented to the Australasian Political Studies Association Conference - University of Tasmania] Hobart, 29 Sep. - 1 Oct. 2003. Disponível em: <http://www.utas.edu.au/government/APSA/ STomblinfinal.pdf $>$. Acesso em: 5 nov. 2008.

TREVISAN, L. Das pressões às ousadias: o confronto entre a descentralização tutelada e a gestão em rede no SUS. Revista de Administração Pública, Rio de Janeiro, v. 41, n. 2, p. 237-254, 2007.

YIN, R. K. Estudo de caso: planejamento e métodos. 3. ed. Porto Alegre: Bookman, 2005.

Recebido em: 17/01/2009

Reapresentado em: 15/05/2009

Aprovado em: 16/07/2009

546 Saúde Soc. São Paulo, v.19, n.3, P. 533-546, 2010 